\title{
O CONTROLE JUDICIAL DE POLÍTICA PÚBLICAS DE SAÚDE DO IDOSO NA PERSPECTIVA DA SUSTENTABILIDADE EM TEMPOS DE PANDEMIA
}

THE JUDICIAL CONTROL OF PUBLIC HEALTH POLICIES FOR THE ELDERLY FROM THE PERSPECTIVE OF SUSTAINABILITY IN TIMES OF

PANDEMICS

\author{
Roberta Terezinha Uvo Bodnar ${ }^{1}$ \\ Cesar Luiz Pasold ${ }^{2}$
}

RESUMO: O presente artigo descreve objetivamente e analisa o Controle Judicial de Políticas Públicas de Saúde do Idoso na perspectiva da Sustentabilidade, especialmente em tempos de Pandemia. A tarefa proposta e ora relatada segue disposta de forma a detalhar sobre a situação do Idoso no Brasil: o cenário atual e projetado frente ao Direito à Saúde, com o intuito de avaliar a necessidade de Controle Judicial de Políticas Públicas de Saúde do Idoso, e, especialmente, sob a perspectiva da Sustentabilidade em tempos de Pandemia. Os resultados permitem concluir que a Sustentabilidade pode ser um relevante parâmetro para o Controle Judicial das Políticas Públicas de Saúde do Idoso. Assim o pode, porque considera também a sua necessária fruição coletiva em um horizonte temporal mais adequado e em plena sintonia, também, com os Objetivos do Desenvolvimento Sustentável. Para realização deste Artigo, na Fase de Investigação foi utilizado o método indutivo e na Fase de Tratamento de Dados foi empregado o método dedutivo.

Palavras-chave: Políticas Públicas; Saúde do Idoso; Sustentabilidade; Pandemia.

ABSTRACT: This article objectively describes and analyzes the Judicial Control of Public

\footnotetext{
${ }^{1}$ Doutoranda em Ciência Jurídica na Universidade do Vale do Itajaí (UNIVALI) em dupla Titulação com Widener University Delaware Law School (EUA). Mestre em Direito pela Universidade Federal de Santa Catarina (UFSC). Professora Convidada da Pós-Graduação em Direito Previdenciário e do Trabalho da UNIVALI. Procuradora Federal (AGU). E-mail: roberta uvo_sc@yahoo.com.br. Lattes: http://lattes.cnpq.br/8027921773653077. ORCID: https://orcid.org/0000-0001-9126-317X.

${ }^{2}$ Doutor em Direito do Estado pela Faculdade de Direito do Largo São Francisco - Universidade de São PauloUSP; Pós Doutor em Direito das Relações Sociais pela Universidade Federal do Paraná-UFPR; Mestre em Instituições Jurídico-Políticas pela UFSC; Mestre em Saúde Pública pela USP. Autor, entre outras obras, de: Ensaio sobre a Ética de Norberto Bobbio. Fpolis: Conceito Editorial, 2008; Função Social do Estado Contemporâneo. 4 ed. Itajaí: Univali-2013- ebook, disponível gratuitamente em: http://siaiapp28.univali.br/LstFree.aspx; Metodologia da Pesquisa Jurídica: Teoria e Prática 14 ed. rev. atual amp. Florianópolis: EMAIS, 2018. Organizador e co-autor, entre outros livros, de: Ensaios sobre Meio Ambiente e Direito Ambiental (Florianópolis Insular). Site profissional: www.cesarluizpasold.com.br. E-mail: clp@cesarluizpasold.com.br. Lattes: http://lattes.cnpq.br/6851573982650146. ORCID: https://orcid.org/0000$\underline{0002-4347-4439}$.
} 
Health Policies for the Elderly from the perspective of Sustainability, especially in times of Pandemic. The proposed and reported task is still arranged in order to describe the situation of the Elderly in Brazil: the current scenario is projected against the Right to Health, in order to assess the need for Judicial Control of Public Health Policies for the Elderly, and especially from the perspective of Sustainability in times of Pandemic. The results allow us to conclude that Sustainability can be a relevant parameter for the Judicial Control of Public Health Policies for the Elderly. It can do so, because it also considers its necessary collective enjoyment in a more adequate time horizon and in full harmony, also, with the Sustainable Development Goals.

Keywords: Public Policy; Elderly Health; Sustainability; Pandemic.

Sumário: 1. O Idoso no Brasil: cenário atual e projetado; 2. Política Pública de Saúde do Idoso; 3. O Idoso e o (in)dispensável Controle Judicial de Políticas Públicas de Saúde no Brasil sob o viés da Sustentabilidade em tempos de Pandemia; 4. Conclusão; 5. Referências.

\section{INTRODUÇÃO}

O presente Artigo tem por objetivo analisar o (in)dispensável Controle Judicial de Políticas Públicas ${ }^{3}$ de Saúde $^{4}$ do Idoso $^{5}$ no Brasil, considerando-se o disposto em comum competência entre União, Estados e Municípios, focando nos termos do artigo 23 da Constituição da República Federativa do Brasil de 1988 (BRASIL, 1988, s.p.).

Com a alteração do perfil populacional, caracterizada pelo aumento progressivo no número dos $\operatorname{Idosos}^{6}$ e, também, considerando as demandas sanitárias nesta fase da vida,

\footnotetext{
${ }^{3}$ De acordo com Juarez Freitas, Políticas Públicas "são programas de Estado Constitucional (mais do que de governo), que reclamam motivada formulação entre alternativas constitucionalmente defensáveis". (FREITAS, 2014, p. 14).

${ }^{4}$ Para a Organização Mundial da Saúde (OMS): "Health is a state of complete physical, mental and social well-being and not merely the absence of disease or infirmity" [A Saúde é um estado de completo bem-estar físico, mental e social e não apenas a ausência de doença ou enfermidade] (tradução livre dos autores do presente texto). (WORLD HEALTH ORGANIZATION, 2020, s.p.).

${ }_{5}^{5}$ Adota-se o conceito cronológico de Idoso, previsto no Estatuto do Idoso, qual seja: "pessoa com idade igual ou superior a 60 (sessenta) anos", nos termos do artigo $1^{\circ}$ da Lei n. 10.741, de $1^{\circ}$ de outubro de 2003. (BRASIL, 2003, s.p.).

${ }^{6}$ Nesse contexto, em 30 de setembro de 2019, declarou as Nações Unidas que se trata de uma das "transformações mais significativas deste século", conforme se transcreve: "In the coming decade, the number of persons aged 60 or over is projected to grow by 46 per cent, making the increase in those officially classified as elderly, one of the 'most significant transformations of this century,' the United Nations declared on Tuesday, marking the International Day of Older Persons. "(negrito conforme o original) [Na próxima década, projeta-se que o número de pessoas com 60 anos ou mais cresça $46 \%$, tornando o aumento daqueles oficialmente classificados como idosos, uma das 'transformações mais significativas deste século', declararam as Nações Unidas na terça-feira, marcando o Dia Internacional das Pessoas Idosas] (tradução livre dos autores do presente texto). (UNITED NATIONS, 2019, s.p.).
} 
surge o desafio na implementação de Políticas Públicas que efetivamente assegurem o Direito à Saúde ao Idoso.

Assim, para garantir esse Direito, é necessário verificar o (in)dispensável Controle Judicial das Políticas Públicas de Saúde do Idoso no Brasil, sob o viés da Sustentabilidade, tão mais em tempos de Pandemia. Nesses, como se está vivenciando e se constatando, são altíssimos os números de Idosos atingidos, destacadamente, em razão do "risco significativo de desenvolver doenças graves se contrairem a doença devido a alterações fisiológicas decorrentes do envelhecimento e possíveis condições de saúde subjacentes”, conforme alerta a Organização Mundial da Saúde ${ }^{7}$.

Como justificativa para a Pesquisa, além da alteração do perfil populacional antes ressaltado, é também oportuno reforçar que o Idoso é o mais vulnerável e, portanto, mais dependente de Políticas Públicas de Saúde consistentes e adequadas. Essa vulnerabilidade é demonstrada de forma contundente no cenário de Pandemia decorrente da COVID-19 ${ }^{8}$.

No Primeiro Item são relatados os resultados da pesquisa com relação ao Idoso no Brasil, apontando-se o conceito de Idoso, o atual e o projetado cenário nacional, de acordo com os dados e as informações Oficiais do Instituto Brasileiro de Geografia e Estatística (IBGE), do Ministério da Saúde (MS), bem como, da Organização Mundial de Saúde (OMS). No Segundo Item, será apresentada a Política Pública de Saúde do Idoso. Por fim, no Terceiro Item, será avaliado o (in)dispensável Controle Judicial de Políticas Públicas de Saúde do Idoso, destacando-se o viés da Sustentabilidade em tempos de Pandemia.

\footnotetext{
${ }^{7}$ Segundo a Organização Mundial da Saúde: "The COVID-19 pandemic is impacting the global population in drastic ways. In many countries, older people are facing the most threats and challenges at this time. Although all age groups are at risk of contracting COVID-19, older people face significant risk of developing severe illness if they contract the disease due to physiological changes that come with ageing and potential underlying health conditions". [A pandemia do COVID-19 está afetando a população global de maneiras drásticas. Em muitos países, os idosos enfrentam mais ameaças e desafios no momento. Embora todas as faixas etárias corram o risco de contrair COVID-19, as pessoas mais velhas correm risco significativo de desenvolver doenças graves se contrairem a doença devido a alterações fisiológicas decorrentes do envelhecimento e possíveis condições de saúde subjacentes.] (tradução livre dos autores do presente texto). (WORLD HEALTH ORGANIZATION, 2020, s.p.)

${ }^{8}$ Segundo a Fundação Oswaldo Cruz (Fiocruz): "Inicialmente chamada de 2019-n-CoV, a infecção provocada pelo novo coronavírus recebeu o nome oficial de covid-19, em 11 de fevereiro: um acrônimo do termo "doença por corona vírus" em inglês (corona virus deceased 2019)" e, nas palavras do infectologista Estevão Portela, vice-diretor de Serviços Clínicos do Instituto Nacional de Infectologia Evandro Chagas (INI/Fiocruz): "Estamos assistindo à ciência em formação. As coisas mudam a cada dia: não só os números da epidemia, mas todos os aspectos. Tudo é muito novo para todos nós”. (BRASIL, 2020, s.p.).
} 
Este Artigo se encerra com as Considerações Finais, nas quais são apresentados pontos conclusivos destacados, seguidos da estimulação à continuidade dos estudos e das reflexões sobre o (in)dispensável Controle Judicial de Políticas Públicas de Saúde do Idoso, especialmente, na perspectiva da Sustentabilidade e em tempos de Pandemia.

Para realização deste Artigo, na Fase de Investigação foi utilizado o método indutivo, o qual significa "pesquisar e identificar as partes de um fenômeno e colecioná-las de modo a ter uma percepção ou conclusão geral” (PASOLD, 2018, p. 95).

Na Fase de Tratamento de Dados o método dedutivo foi empregado.

O Relatório dos Resultados que é expresso no presente Artigo foi composto na base lógica indutiva.

No todo, sob o suporte das Técnicas; do Referente ${ }^{9}$, da Categoria ${ }^{10}$, do Conceito Operacional $^{11}$, da Pesquisa Bibliográfica ${ }^{12}$ e da Pesquisa Jurisprudencial.

\section{O IDOSO NO BRASIL: CENÁRIO ATUAL E PROJETADO}

No Brasil é adotado o conceito cronológico de Idoso, o qual conforme o $\operatorname{artigo} 1^{\circ}$ da Lei n. 10.741, de $1^{\circ}$ de outubro de 2003 (Estatuto do Idoso) ${ }^{13}$, é considerada Idosa a pessoa “com idade igual ou superior a 60 (sessenta) anos".

Apesar de ser adotado o conceito cronológico de Idoso no Brasil, ressalta-se que para a Psicologia a idade funcional é uma classificação mais significativa, a qual consiste na “capacidade de uma pessoa interagir em um ambiente físico e social em comparação com outros da mesma idade cronológica" (PAPALIA; FELDMAN, 2013, p. 574), por exemplo:

\footnotetext{
9 “[...] a explicitação prévia do(s) motivo(s), do(s) objetivo(s) e do produto desejado, delimitando o alcance temático e de abordagem para a atividade intelectual, especialmente para uma pesquisa." (PASOLD, 2018, p. 62). (negrito conforme o original)

10 “[...] palavra ou expressão estratégica à elaboração e/ou à expressão de uma ideia.” (PASOLD, 2018, p. 31) (negrito conforme o original).

11 “[...] uma definição para uma palavra ou expressão, com o desejo de que tal definição seja aceita para os efeitos das ideias que expomos [...]". (PASOLD, 2018, p. 43). (negrito conforme o original)

12 "Técnica de investigação em livros, repertórios jurisprudenciais e coletâneas legais. (PASOLD, 2018, p. 217).

${ }^{13}$ Além disso, o próprio Estatuto do Idoso prevê idade diferenciada para dois direitos: o Benefício de Prestação Continuada (BPC), previsto no artigo 203, inciso V, da CRFB/1988 e disciplinado pela Lei Orgânica de Assistência Social (LOAS), e a gratuidade nos transportes públicos urbanos e semiurbanos, ambos destinados ao idoso com idade igual ou superior a 65 (sessenta e cinco) anos, nos termos dos artigos 34 e 39 do Estatuto do Idoso. (BRASIL, 2003, s.p.).
} 
"uma pessoa de 90 anos que está com boa saúde pode ser funcionalmente mais jovem do que uma de 65" (PAPALIA; FELDMAN, 2013, p. 574).

O fato é que o Mundo está no centro de uma transição do processo demográfico única e irreversível, conforme explica a Organização das Nações Unidas (ONU) (2020, s.p.), “que irá resultar em mais populações idosas em todos os lugares" e, nos termos da World Health Organization (2020, s.p.):

People worldwide are living longer. Today, for the first time in history, most people can expect to live into their sixties and beyond. By 2050, the world's population aged 60 years and older is expected to total 2 billion, up from 900 million in 2015. Today, 125 million people are aged 80 years or older. By 2050, there will be almost this many (120 million) living in China alone, and 434 million people in this age group worldwide. By $2050,80 \%$ of all older people will live in low- and middle-income countries ${ }^{14}$.

Consequentemente, o cenário do Brasil não é diverso, pois, segundo as Projeções do Instituto Brasileiro de Geografia e Estatística (IBGE) (BRASIL, 2020, s.p.) até 2060, publicadas em 2018: para 2050 a Proporção de Pessoas por Grandes Grupos Etários, maiores de sessenta anos é de 28,45, com índice de envelhecimento de 142,21\% e idade mediana de 43,92 .

Nesse contexto, ilustra-se com as "Projeções e Estimativas da População do Brasil", disponibilizadas pelo IBGE (BRASIL, 2020, s.p.):

14 "Pessoas em todo o mundo estão vivendo mais. Hoje, pela primeira vez na história, a maioria das pessoas pode esperar viver até os sessenta anos e além. Até 2050, a população mundial com 60 anos ou mais deve totalizar 2 bilhões, ante 900 milhões em 2015. Hoje, 125 milhões de pessoas têm 80 anos ou mais. Até 2050, haverá quase tantos (120 milhões) vivendo somente na China e 434 milhões de pessoas nessa faixa etária em todo o mundo. Até $2050,80 \%$ de todos os idosos viverão em países de baixa e média renda." (tradução livre) (WORLD HEALTH ORGANIZATION, 2020, s.p.). 


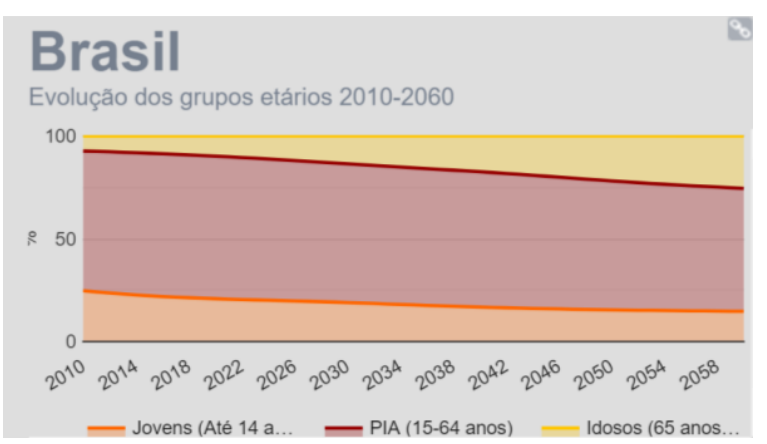

Figura 1: Evolução dos Grupos Etários 2010-2060.

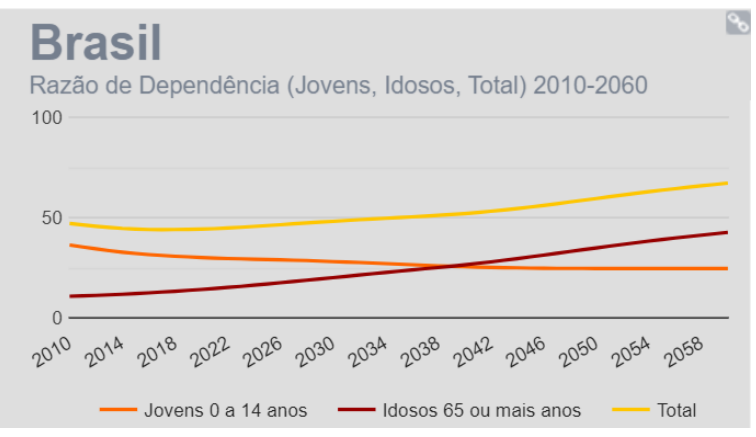

Figura 2: Razão de Dependência 2010-2060.

Corroboram com esses números e projeções do Brasil, os índices previstos pela World Health Organization (WHO) (2018, s.p.):

The pace of population ageing around the world is also increasing dramatically. France had almost 150 years to adapt to a change from $10 \%$ to $20 \%$ in the proportion of the population that was older than 60 years. However, places such as Brazil, China and India will have slightly more than 20 years to make the same adaptation $^{15}$.

Portanto, a mudança no perfil da população brasileira é perceptível, eis que há a cada dia um número maior de pessoas idosas e as projeções são nítidas para o aumento da população Idosa no Brasil, dados indispensáveis para a formulação de Políticas Públicas, tão mais para àquelas que objetivam proteger, promover e garantir o Direito à Saúde do Idoso.

O Ministério da Saúde (BRASIL, 2020, s.p.), ao tratar sobre a "Saúde da pessoa idosa: prevenção e promoção à saúde integral”, assim, apresenta o cenário brasileiro:

A transição demográfica brasileira apresenta características peculiares e demonstra grandes desigualdades sociais no processo de envelhecimento. Esse processo impactou e trouxe mudanças no perfil demográfico e epidemiológico em todo país, produzindo demandas que requerem respostas das políticas sociais, implicando em novas formas de cuidado, em especial aos cuidados prolongados $\mathrm{e}$ à atenção domiciliar.

15 “O ritmo do envelhecimento da população em todo o mundo também está aumentando drasticamente. A França teve quase 150 anos para se adaptar a uma mudança de $10 \%$ para $20 \%$ na proporção da população com mais de 60 anos. No entanto, lugares como Brasil, China e Índia terão um pouco mais de 20 anos para fazer a mesma adaptação.” (tradução livre). (WORLD HEALTH ORGANIZATION, 2018, s.p.). 
Nesse sentido, Alexandra Lopes (LOPES, 2017, p. 160) ao escrever sobre "Envelhecimento, dependências e fragilidades: tensões e desafios no Portugal contemporâneo", os quais podem ser tomados de exemplo para o Brasil, explica, entre os contextos das necessidades de cuidados no campo das Políticas Públicas para os cuidados, que a distribuição de riscos do Idoso é muito desigual, não apenas devido a uma série de eventos e condições que não podem ser totalmente controlados, como a viuzes, mas, também, "e sobretudo, devido a uma série de dimensões de vulnerabilidade que são socialmente construídas e têm uma base estrutural, dimensões que muitas vezes se desnvolvem ao longo da vida".

Conforme Alexandre Leopold Busse e Wilson Jacob Filho (BUSSE; JACOB FILHO, 2015, p. 3-4):

\begin{abstract}
Muitos idosos passarão a morar sozinhos ou apenas com seus cônjuges. [...] Assim é previsível que, em muitos países, aumente o número de idosos dependentes, sem parentes que possam lhes cuidar e ainda sem cuidadores formais treinados ou instituições capazes de recebe-los. Entretanto, nã há exemplos históricos disponíveis para orientar as tomadas de decisões em relação a essas mudanças sociais, por isso, os países terão de contar com novas análises para propor novas políticas públicas.
\end{abstract}

Ainda, o Ministério da Saúde (BRASIL, 2020, s.p.) traça o Perfil Epidemiológico da População Idosa, registrando que é "caracterizado pela tripla carga de doenças com forte predomíno das condições crônicas, prevalências de elevada mortalidade e morbidade por condições agudas decorrentes de causas externas e agudizações de condições crônicas". Esse Perfil é considerado e ratificado na "Figura 1: Razão de Dependência 2010-2060" da "Projeções e Estimativas da População do Brasil", acima ilustradas e disponibilizadas pelo IBGE (BRASIL, 2020, s.p.).

No entanto, alerta o Ministério da Saúde (BRASIL, 2020, s.p.) que "a maioria dos idosos é portadora de doenças ou disfunções orgânicas, mas cabe destacar que esse quadro não significa necessariamente limitação de suas atividades, restrição da participação social ou do desempenho do seu papel social". 
Por fim, esses dados, percentuais e perspectivas deverão ser avaliados em conjunto com os resultados em decorrência da Pandemia instalada pela COVID-19 ${ }^{16}$, a qual impactará significativamente nas Políticas Públicas de Saúde do Idoso. Afinal, o vírus está atingindo consideravelmente os Idosos, em razão do "risk of developing severe illness if they contract the disease due to physiological changes that come with ageing and potential underlying health conditions", conforme explica a World Health Organization ${ }^{17}$, consequentemente, o Direito à Saúde dos Idosos será o mais impactado com esta Pandemia.

A título ilustrativo, cita-se as estatísticas do Centers for Disease Control and Prevention (CDC), integrante do Departamento de Saúde e Serviços Humanos dos Estados Unidos da América, revisadas em 11 de setembro de 2020, expressando que: 8 (oito) em cada 10 (dez) mortes reportadas nos Estados Unidos da América ocorreram em adultos com 65 (sessenta e cinco) anos ou mais (UNITED STATES, 2020, s.p.) ${ }^{18}$.

No Brasil, colhe-se do Ministério da Saúde (BRASIL, 2020, s.p.), os seguintes dados de hospitalização por faixa etária e sexo, dos quais se depreende a alta utilização hospitalar pelo Idoso:

\footnotetext{
${ }^{16}$ Segundo a Fundação Oswaldo Cruz (Fiocruz): "Inicialmente chamada de 2019-n-CoV, a infecção provocada pelo novo coronavírus recebeu o nome oficial de covid-19, em 11 de fevereiro: um acrônimo do termo "doença por corona vírus" em inglês (corona virus deceased 2019)" e, nas palavras do infectologista Estevão Portela, vice-diretor de Serviços Clínicos do Instituto Nacional de Infectologia Evandro Chagas (INI/Fiocruz): "Estamos assistindo à ciência em formação. As coisas mudam a cada dia: não só os números da epidemia, mas todos os aspectos. Tudo é muito novo para todos nós". (BRASIL, 2020, s.p.).

${ }^{17}$ Segundo a Organização Mundial da Saúde: "The COVID-19 pandemic is impacting the global population in drastic ways. In many countries, older people are facing the most threats and challenges at this time. Although all age groups are at risk of contracting COVID-19, older people face significant risk of developing severe illness if they contract the disease due to physiological changes that come with ageing and potential underlying health conditions". [A pandemia do COVID-19 está afetando a população global de maneiras drásticas. Em muitos países, os idosos enfrentam mais ameaças e desafios no momento. Embora todas as faixas etárias corram o risco de contrair COVID-19, as pessoas mais velhas correm risco significativo de desenvolver doenças graves se contrairem a doença devido a alterações fisiológicas decorrentes do envelhecimento e possíveis condições de saúde subjacentes.] (tradução livre dos autores do presente artigo). (WORLD HEALTH ORGANIZATION, 2020, s.p.).

${ }^{18}$ Importante esclarecer que nos Estados Unidos da América é considerada Idosa a pessoa com idade igual ou superior a 65 (sessenta e cinco) anos e no Brasil, conforme já explicado, é considerada Idosa a pessoa com idade igual ou superior a 60 (sessenta) anos.
} 


\section{SRAG hospitalizado por faixa etária e sexo}

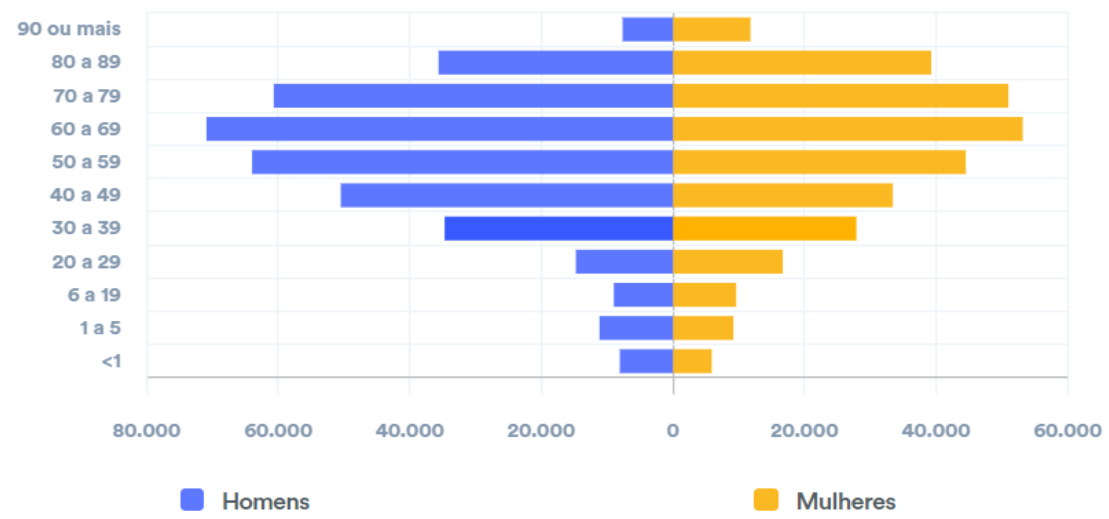

Fonte: SIVEP-Gripe/SVS/MS. Brasil, 2020

Figura 3: SRAG hospitalizado por faixa etária e sexo.

Portanto, a mudança no perfil da população brasileira é perceptível, eis que há a cada dia um número maior de pessoas idosas e as projeções são nítidas para o aumento da população dos Idosos no Brasil, sendo os dados e os percentuais indispensáveis para a formulação de Políticas Públicas, tão mais para àquelas que objetivam proteger, promover e garantir o Direito à Saúde do Idoso, inclusive, em tempos de Pandemia.

\section{POLÍTICA PÚBLICA DE SAÚdE DO IDOSO.}

O Estado Brasileiro institui diretrizes com a finalidade de garantir a concretização de Direitos Sociais Fundamentais que dependem da sua intervenção, como o caso do Direito à Saúde, inclusive, relacionado ao Idoso. Essas diretrizes constituem as Políticas Públicas.

Para Juarez Freitas (FREITAS, 2014, p. 148) ${ }^{19}$ as Políticas Públicas não podem ser consideradas meros programas governamentais e apresenta os elementos caracterizadores das políticas públicas, quais sejam:

\footnotetext{
${ }^{19}$ De acordo com Juarez Freitas, Políticas Públicas "são programas de Estado Constitucional (mais do que de governo), que reclamam motivada formulação entre alternativas constitucionalmente defensáveis". (FREITAS, 2014, p. 148).
} 
(a) são programas de Estado Constitucional (mais do que de governo), que reclamam motivada formulação entre alternativas constitucionalmente defensáveis, (b) processados por atos de cognição e de vontade dos múltiplos atores políticos, no intuito de solver problemas sociais concretos, e que (c) devem consubstanciar, na prática governamental, prioridades cogentes, geradoras de benefícios excedentes aos custos diretos e indiretos.

Flávio Roberto de Almeida Heringer, após Pesquisar: “Quantas políticas públicas há no Brasil? O problema da imprecisão conceitual para a avaliação de políticas públicas" e mesmo com subsídios dos Ministérios do Governo Federal e sob o viés ontológico, tipológico e teleológico, concluiu que:

[...] a pergunta básica formulada para o presente estudo não pode ser respondida de maneira objetiva, tendo em vista a imprecisão conceitual no que tange à essência da política pública como manifestação de uma estratégia de solução de problemas. Há muito que ser feito nesse sentido. (HERINGER, 2018, p. 66)

Na referida Pesquisa, o mencionado Autor (HERINGER, 2018, p. 48) expressa, após analisar a resposta do Ministério da Saúde, que a Política Pública para o referido Órgão é: “construída a partir das competência de cada setor e revela, também, diferentes níveis de entendimento da demanda formulada" ${ }^{20}$.

As Políticas Públicas de Saúde do Idoso no Brasil são fundamentadas por intermédio da Constituição da República Federativa do Brasil de 1988 (CRFB/1988) (BRASIL, 1988, s.p.), encontram-se dispositivos versando sobre a Saúde nos artigos 6º 170; 194, parágrafo único e incisos I e V; 198, inciso II; e, é em seu artigo 196, que a Saúde está constitucionalizada com todo o detalhamento como Direito de todos e dever do Estado, nos seguintes termos:

Art. 196. A saúde é direito de todos e dever do Estado, garantido mediante políticas sociais e econômicas que visem à redução do risco de doença e de outros agravos e ao acesso universal e igualitário às ações e serviços para sua promoção, proteção e recuperação.

${ }^{20}$ Sic para "competência” no singular. 
A Política Nacional do Idoso (BRASIL, 1994, s.p.), em seu Capítulo IV, que trata sobre "Das Ações Governamentais", dispõe entre a sua implementação, no artigo 10, inciso II, as competências dos Órgãos e Entidades Públicos, na área da Saúde ${ }^{21}$.

O Estatuto do Idoso (BRASIL, 2003, s.p.) complementa a CRFB/1988, assim como a Política Nacional do Idoso, em seu Capítulo IV, artigo 15, determinando:

Art. 15. É assegurado a atenção integral à saúde do idoso, por intermédio do Sistema Único de Saúde - SUS, garantindo-lhe o acesso universal e igualitário, em conjunto articulado e contínuo das ações e serviços, para a prevenção, promoção, proteção e recuperação da saúde, incluindo a atenção especial às doenças que afetam preferencialmente os idosos.

E, o $§ 2^{\circ}$ do artigo 15 do Estatuto do Idoso (BRASIL, 2003, s.p.) impõe ao Poder Público o fornecimento gratuito de medicamentos, em especial os de uso continuado, bem como próteses, órteses e outros recursos relativos ao tratamento, habilitação ou reabilitação.

A Política Nacional de Saúde da Pessoa Idosa (BRASIL, 2006, s.p.), instituída pela Portaria n. 2.528, de 19 de outubro de 2006, do Ministério da Saúde, reconheceu os avanços na legislação brasileira, quanto aos cuidados da população Idosa, bem como, registrou que “a prática ainda é insatisfatória”. Isto é, já no ano de $2006^{22}$, o Poder Executivo denunciava a violação à proteção do Direito à Saúde destinado ao Idoso.

${ }^{21}$ Eis as competências dos Órgãos e Entidades Públicos, na área da Saúde: “a) garantir ao idoso a assistência à saúde, nos diversos níveis de atendimento do Sistema Único de Saúde; b) prevenir, promover, proteger e recuperar a saúde do idoso, mediante programas e medidas profiláticas; c) adotar e aplicar normas de funcionamento às instituições geriátricas e similares, com fiscalização pelos gestores do Sistema Único de Saúde; d) elaborar normas de serviços geriátricos hospitalares; e) desenvolver formas de cooperação entre as Secretarias de Saúde dos Estados, do Distrito Federal, e dos Municípios e entre os Centros de Referência em Geriatria e Gerontologia para treinamento de equipes interprofissionais; f) incluir a Geriatria como especialidade clínica, para efeito de concursos públicos federais, estaduais, do Distrito Federal e municipais; g) realizar estudos para detectar o caráter epidemiológico de determinadas doenças do idoso, com vistas a prevenção, tratamento e reabilitação; e h) criar serviços alternativos de saúde para o idoso". (BRASIL, 1994, s.p.).

${ }^{22}$ Eis o texto na íntegra: "Assim, embora a legislação brasileira relativa aos cuidados da população idosa seja bastante avançada, a prática ainda é insatisfatória. A vigência do Estatuto do Idoso e seu uso como instrumento para a conquista de direitos dos idosos, a ampliação da Estratégia Saúde da Família que revela a presença de idosos e famílias frágeis e em situação de grande vulnerabilidade social e a inserção ainda incipiente das Redes Estaduais de Assistência à Saúde do Idoso tornaram imperiosa a readequação da Política Nacional de Saúde da Pessoa Idosa (PNSPI)". (BRASIL, 2020, s.p.). 
Tratando-se de violação à proteção dos Direitos da Saúde do Idoso, é indispensável lembrar da situação do Idoso no Mundo, consequentemente, no Brasil ${ }^{23}$, diante da Pandemia instalada pela COVID-1924.

Merecem atenção as palavras da perita independente das Nações Unidas para o Direito das Pessoas Idosas, Rosa Kornfeld-Matte, quando pontua: “a necessidade urgente de uma abordagem holística de direitos humanos que garanta igual realização de todos os direitos, incluindo acesso a serviço de saúde" (NAÇÕES UNIDAS BRASIL, 2020, s.p.).

Ainda, World Health Organization instituiu a "Decade of Healthy Ageing" 25 , ou seja, a Década do Envelhecimento Saudável (2020-2030), com o objetivo de reunir Governos, Sociedade Civil, Agências Internacionais, Profissionais, Academia, Mídia e Setor Privado por dez anos de ação combinada, catalítica e colaborativa para melhorar a vida de Idosos, suas famílias e as comunidades em que vivem ${ }^{26}$. Afinal, ainda, segundo aponta a World Health Organization:

A decade of concerted global action on Healthy Ageing is urgently needed. Already, there are more than 1 billion people aged 60 years or older, with most living in low- and middle-income countries. Many do not have access to even the basic resources necessary for a life of meaning and of dignity. Many others confront multiple barriers that prevent their full participation in society ${ }^{27}$.

\footnotetext{
${ }^{23}$ A título ilustrativo, transcreve-se a notícia publicada no Diário do Nordeste, intitulada: "Idoso com suspeita de Covid-19 morre à espera de leito de UTI na UPA do Bom Jardim", contendo o seguinte texto: "Após sete dias internado na Unidade de Pronto Atendimento (UPA) do bairro Bom Jardim, à espera de um leito de UTI, o idoso Ivanildo Vieira Damasceno, 66, faleceu, neste domingo (3), com suspeita de Covid-19. [...]" (DIÁRIO DO NORDESTE, 2020, s.p.).

${ }^{24}$ Segundo a Fundação Oswaldo Cruz (Fiocruz): "Inicialmente chamada de 2019-n-CoV, a infecção provocada pelo novo coronavírus recebeu o nome oficial de covid-19, em 11 de fevereiro: um acrônimo do termo "doença por corona vírus" em inglês (corona virus deceased 2019)" e, nas palavras do infectologista Estevão Portela, vice-diretor de Serviços Clínicos do Instituto Nacional de Infectologia Evandro Chagas (INI/Fiocruz): "Estamos assistindo à ciência em formação. As coisas mudam a cada dia: não só os números da epidemia, mas todos os aspectos. Tudo é muito novo para todos nós". (BRASIL, 2020, s.p.).

${ }^{25}$ O Documento de Proposta da Década está disponível em: www.who.int/docs/default-source/decade-ofhealthy-ageing/final-decade-proposal/decade-proposal-final-apr2020-en.pdf?sfvrsn=b4b75ebc_5.

${ }^{26}$ Consta no original: "The Decade of Healthy Ageing (2020-2030) is an opportunity to bring together governments, civil society, international agencies, professionals, academia, the media, and the private sector for ten years of concerted, catalytic and collaborative action to improve the lives of older people, their families, and the communities in which they live." (WORLD HEALTH ORGANIZATION, 2020, s.p.)

27 "Uma década de ação global concertada para o Envelhecimento Saudável é necessária com urgência. Já existem mais de 1 bilhão de pessoas com 60 anos ou mais, a maioria vivendo em países de baixa e média renda. Muitos não têm acesso nem aos recursos básicos necessários para uma vida com sentido e dignidade. Muitos
} 
Por fim, quanto à implementação prática do Direito à Saúde no Brasil:

Apesar dos avanços no plano legislativo, muitos desafios ainda são constatados na implementação prática do direito à saúde. Pois os serviços de saúde que são disponibilizados concretamente para a população, especialmente para os mais fragilizados socialmente, não corresponde à pauta ambiciosa e generosa prevista pelo Constituinte. Esse fato, aliado à falta de articulação adequada entre os entes públicos responsáveis pela implementação das políticas sanitárias, gera uma significativa judicialização do tema, circunstância essa que torna os juízes também partícipes da gestão do sistema público de saúde, considerando o elevado potencial de impacto econômico das suas decisões (BODNAR, 2013, p. 302).

Também, com base nesses ensinamentos da prática, Roberta Terezinha Uvo Bodnar (UVO BODNAR, 2015, p. 57), ao analisar a "Gestão e implementação de políticas públicas de saúde", e contatar que o Poder Executivo e o Poder Legislativo, não têm atendido aos anseios pelos quais lhes fora atribuída a legitimidade e a competência de gestão e de implementação de Políticas Públicas para a efetivação de Direito à Saúde, conclui que:

Portanto, quando o Estado é omisso, o Poder Judiciário assume uma importante missão na realização do controle de políticas públicas de saúde, uma vez que por intermédio de suas decisões judiciais, na qualidade de guardião dos direitos e garantias fundamentais, tem possibilitado que o direito à saúde não permaneça apenas como uma "letra morta na lei".

Assim, considerando que os "tribunais, governantes e legisladores têm o papel solidário de projeção e realização de uma sociedade em que os direitos fundamentais sejam debatidos e concretizados" (DIAS, 2012, p. 161), em caso de violação ou de omissão por parte do Poder Legislativo e/ou do Executivo, resta verificar a (in)dispensável atuação por meio do Poder Judiciário com o objetivo de proteger o Direito da Saúde do Idoso, sob o viés da Sustentabilidade e, especialmente, em tempos de Pandemia.

\section{O (IN)DISPENSÁVEL CONTROLE JUDICIAL DE POLÍTICAS PÚBLICAS DE SAÚDE DO IDOSO NO BRASIL SOB O VIÉS DA SUSTENTABILIDADE EM}

outros enfrentam múltiplas barreiras que impedem sua plena participação na sociedade" (tradução livre dos autores do presente artigo). (WORLD HEALTH ORGANIZATION, 2020, s.p.). 


\section{TEMPOS DE PANDEMIA}

A Separação das Funções Estatais ou dos Poderes ${ }^{28}$ encontra como fundamento ético e jurídico a contenção do arbítrio ou do abuso estatal em detrimento dos Direitos Fundamentais $^{29}$. Assim, quando o Poder Judiciário impõe condutas à Administração Pública exatamente para que a omissão não lese Direitos Fundamentais, como é o caso da proteção ao Direito à Saúde do Idoso, não há qualquer ilegitimidade nesta intervenção.

Ao contrário, conforme a lição de Zenildo Bodnar (BODNAR, 2012, s.p.): “o controle das omissões injurídicas está respaldado nas razões legitimantes da própria separação dos poderes estatais" ${ }^{30}$.

Nesse sentido, Jean Carlos Dias (DIAS, 2012, p. 190;206), ao tratar em sua Obra sobre "o Controle Judicial de Políticas Públicas”, explica que “o controle judicial está intimamente relacionado a uma Democracia Constitucional. Uma vez que uma sociedade estrutura-se sob a forma de um Estado de Direito, a linha de condução política é a submissão à proteção dos direitos fundamentais.”, e, o referido Autor, conclui:

A legitimação das decisões deve, assim, ser refletida pela atuação social nos procedimentos perante os tribunais, capazes de tornar o juiz gestor, como um destinatário passível de refletir acerca as demandas sociais e se colocar como agente estatal apto a exercer controle de opções políticas.

Recordando-se das objeções ao Controle Judicial de Políticas Públicas, cumpre registrar, segundo Sérgio Cruz Arenhart (ARENHART, 2020, p. 2), que "o controle jurisdicional de políticas públicas, ainda que se possa, academicamente, questionar sob diversas óticas, é um fato inquestionável”.

${ }^{28}$ O Superior Tribunal de Justiça ao julgar o Tema 106, deixou registrado que: “[...] nos termos da jurisprudência do Supremo Tribunal Federal e desta Corte Superior de Justiça, não há que se falar em violação ao princípio da separação dos poderes, quando o Poder Judiciário intervém no intuito de garantir a implementação de políticas públicas, notadamente, como no caso em análise, em que se busca a tutela do direito à saúde.”. (BRASIL, 2020, s.p.).

${ }^{29}$ Nos mesmos termos, escreve Zenildo Bodnar, porém, expressando os Direitos Humanos, os quais são mais amplos que os Direitos Fundamentais, segundo o conceito de J. J. Canotilho (CANOTILHO, José Joaquim Gomes. Direito constitucional e teoria da constituição. 7 ed. 21 reimp. Coimbra: Almedina, 2019). (BODNAR, 2012, s.p.).

${ }^{30}$ Conforme as palavras de Jean Carlos Dias: "Não se trata, assim, de assumir o papel do Executivo ou Legislativo como elaborador e executor de políticas, e sim de definir se essas são efetivamente compatíveis com o sistema de direitos básicos assegurados institucionalmente”. (DIAS, 2016, p. 176). 
A Tutela Jurisdicional da Saúde do Idoso no Brasil foi objeto de estudo por Roberta Terezinha Uvo Bodnar, em sua Dissertação de Mestrado intitulada: "A tutela jurisdicional da saúde do idoso no Brasil e a matriz disciplinar interpretativa dos Tribunais na perspectiva da fraternidade", na qual foram analisadas as decisões proferidas, inclusive, pelos Tribunais Superiores, chegando-se a seguinte conclusão:

[...] o Poder Judiciário detém uma atuação digna de registro, sensível e fraterna para com as demandas voltadas às políticas públicas de saúde, especialmente as pertinentes à saúde do idoso, as quais têm sido decididas com base em princípios e valores previstos na Constituição da República Federativa do Brasil de 1988, e não raro fundamentadas na fraternidade, e em tal razão, pode-se dizer: sem sombra de dúvidas, a fraternidade se faz presente, conferindo teoria e prática, guardando expressão e força, gerando eficácia e exequibilidade, e, sobretudo, detém capacidade para incutir o mais alto grau da "dignidade de nossa comum humanidade", o que anseia o devido reconhecimento (UVO BODNAR, 2015, p. $150)$.

Portanto, verifica-se que por intermédio do Poder Judiciário, o Direito Fundamental à Saúde do Idoso, pode ser efetivado, inclusive, em uma perspectiva da Sustentabilidade. Isso porque a Constituição da República Federativa do Brasil de 1988 confere a esta Instituição a responsabilidade de (re)afirmar o amplo conjunto de Direitos Fundamentais Sociais Prestacionais, assim como os Princípios e Objetivos Fundamentais da República.

A perspectiva da Sustentabilidade é um critério racional importante para a definição dos limites e das possibilidades de intervenção jurisdicional nas escolhas e alocações públicas. Todo Direito Prestacional Social apresenta também um custo econômico ${ }^{31}$ e, especialmente, em tempos de crise e escassez - como no cenário de uma Pandemia - nem sempre será possível o provimento ideal de todos os Direitos Sociais Prestacionais, sendo indispensável a definição de critérios decisórios adequados.

De acordo com Paulo Márcio Cruz e Zenildo Bodnar (CRUZ; BODNAR, 2012, P. 107) "a sustentabilidade deve ser construída e consolidada a partir do aporte científico de

${ }^{31}$ Conforme destaca Juarez Freitas: "a projeção raciocinada de consequências, acompanhada de explícitos argumentos em prol da superioridade de benefícios líquidos-monetizáveis e não-monetizáveis-no cotejo com a integralidade de custos estimados, diretos e indiretos, sociais, econômicos e ambientais." (FREITAS, Juarez, 2018, p. 47). 
diversos campos do saber e deve integrar a base formativa de todas as teorias políticas, sociais, econômicas e jurídicas na atualidade” e, ainda, os referidos Autores completam:

Nessa interação sinérgica entre os campos do conhecimento, o jurídico deve desempenhar um protagonismo de liderança no intuito de fornecer uma estrutura institucional e normativa para a consolidação da sustentabilidade também enquanto princípio fundacional juridicizado com força otimizadora e dirigente. (CRUZ; BODNAR, 2012, p. 107)

O termo Sustentável, segundo as pesquisas realizadas por Alexandre André Feil e Dusan Schreiber surgiu em 1713, quando:

Hans Carl Von Carlowitz, na Alemanha, influenciado pelas ideias de Evelyn (1664) e de Colbert (1669) sobre a rápida devastação florestal da Europa, publica o livro Sylvicultura Oeconomica oder Anweisung zur wilden Baumzucht. Centrase na escassez da madeira, demonstrando alternativas de consumo eficiente, reaproveitamento de energia, reflorestamento e substituição da madeira pelo fóssil, para a busca do equilíbrio entre o corte e a renovação da madeira, com vistas à sua utilização contínua e perpétua. (FEIL; SCHREIBER, 2020, s.p.)

No entanto, conforme descrito pelas Nações Unidas em sua Página Oficial (NAÇÕES UNIDAS BRASIL, 2020, s.p.), “o movimento ambientalista ganhou novo impulso em 1962 com a publicação do livro de Rachel Carson, 'A Primavera Silenciosa' [...] destacou a necessidade de respeitar o ecossistema em que vivemos para proteger a saúde humana e o meio ambiente." 32 e, esta Obra foi de fundamental importância para se estabelecer o conceito de Sustentabilidade, assim como, de Desenvolvimento Sustentável, inclusive, na Conferência das Nações Unidas sobre o Desenvolvimento Sustentável (Rio $+20)^{33}$.

Concluem Paulo Márcio Cruz e Zenildo Bodnar que:

\footnotetext{
32 "Primavera Silenciosa (1962), de Rachel Carson, uma obra literária de denúncia e divulgação científica, em que a autora, seguindo o viés de uma 'fábula do amanhã', expõe o perigo dos pesticidas, arrastando tudo e todos a um lugar comum, onde as árvores não davam folhas, os animais morriam, os rios contaminados não tinham peixes e, principalmente, os pássaros, outrora cantores da primavera, quedavam sem voz, mortos pela contaminação dos agrotóxicos, de onde decorre o título do livro". (UVO BODNAR, 2019, p. XIV).

33 "Desenvolvimento sustentável é o modelo que prevê a integração entre economia, sociedade e meio ambiente. Em outras palavras, é a noção de que o crescimento econômico deve levar em consideração a inclusão social e a proteção ambiental”. (COMITÊ NACIONAL DE ORGANIZAÇÃO RIO+20, 2020, s.p.).
} 
Apesar da amplitude conceitual já alcançada é muito importante que os avanços prossigam, não apenas no aspecto formal, mas principalmente na identificação de estratégias e mecanismos para tornar concreto os estes nobres objetivos preconizados para a melhora contínua da qualidade da vida em todas as suas formas (CRUZ; BODNAR, 2012, p. 111)

Essa breve digressão é relevante para que se compreenda que a Sustentabilidade é um conceito amplo, interdisciplinar, histórico, relacional e que apresenta múltiplas dimensões. Cuida do ambiental e da vida, sem esquecer o social e o econômico, e apresenta o grande mérito de considerar, inclusive, um horizonte temporal alongado. Nas alocações e escolhas públicas, também será indispensável a seleção de prioridades e a proteção de mínimos intangíveis, sempre num contexto de limites e de escassez.

Ao expor sobre o tema, Juarez Freitas, além de propor o critério em um sentido geral de controle de Políticas Públicas, enfatiza os seguintes méritos:

[...] induz a internalização das externalidades negativas; realça o peso consorciado de justificativas econômicas e não-econômicas; destaca e preserva valores intrínsecos; desvela ônus da passividade omissivista; torna nítida a importância de padronizações sensatas; positivas; permite o julgamento dos projetos com horizonte dilatado; facilita a rejeição das soluções reducionistas; favorece um laboriosa gestão de riscos; expande as alternativas inovadoras e contém o impulsivismo direcionado a recompensas efêmeras que sacrificam o amanhã. (FREITAS, 2018, p. 47)

No Poder Judiciário a estratégia pode ser destacada por meio da Portaria n. 133/2018, a qual instituiu no Conselho Nacional de Justiça (BRASIL, 2018, s.p.), o Comitê Interinstitucional destinado a avaliar a integração das metas do Poder Judiciário às metas e indicadores dos Objetivos de Desenvolvimento Sustentável (ODS), Agenda 2030, e elaborar relatório de trabalho com apoio de todos os Tribunais do País.

Registre-se que, entre os Objetivos de Desenvolvimento Sustentável (ODS) (NAÇÕES UNIDAS BRASIL, 2020, s.p.), encontra-se o Objetivo 3 assim versado: "assegurar uma vida saudável e promover o bem-estar para todos, em todas as idades". Assim formulado, destaque-se para a percepção do contexto nacional: o Direito Fundamental à Saúde. 
Depreende-se do Encontro Ibero-Americano da Agenda 2030 no Poder Judiciário (BRASIL, 2019, s.p.), realizado em agosto de 2019, que “assim, se o Poder Judiciário batalha por uma sociedade ética, íntegra, pacífica, solidária, fraterna e próspera, também contribui para o alcance da Agenda 2030 e dela não pode se excluir. Ao revés, deve mostrar aos cidadãos o quanto contribui para esse pacto global."

A título de exemplo desta "batalha por uma sociedade ética, íntegra, pacífica, solidária, fraterna e próspera" (BRASIL, 2019, s.p.) por meio do Poder Judiciário, merece menção que perante o Superior Tribunal de Justiça (STJ), foi julgado o Tema 106 e fixada a seguinte Tese $^{34}$ :

A concessão dos medicamentos não incorporados em atos normativos do SUS exige a presença cumulativa dos seguintes requisitos:

i) Comprovação, por meio de laudo médico fundamentado e circunstanciado expedido por médico que assiste o paciente, da imprescindibilidade ou necessidade do medicamento, assim como da ineficácia, para o tratamento da moléstia, dos fármacos fornecidos pelo SUS;

ii) incapacidade financeira de arcar com o custo do medicamento prescrito;

iii) existência de registro do medicamento na ANVISA, observados os usos autorizados pela agência.

Para tanto, tratando-se de julgamento de Recurso Repetitivo, nos termos do Código de Processo Civil (BRASIL, 2015, s.p.), decorre que, tendo sido a decisão já publicada, a Tese firmada pelo Tribunal Superior deve ser seguida pelos demais Órgãos do Poder Judiciário (artigo 1.040, inciso III), em nítido respeito aos seus propósitos.

Esses, são: "batalha por uma sociedade ética, íntegra, pacífica, solidária, fraterna e próspera” (BRASIL, 2019, s.p.), quanto ao item 3 dos Objetivos de Desenvolvimento Sustentável: “assegurar uma vida saudável e promover o bem-estar para todos, em todas as idades".

\footnotetext{
${ }^{34}$ Tese definida no Acórdão dos Embargos de Declaração, publicado no DJe de 21 de setembro de 2018, o qual modulou os efeitos do Recurso Repetitivo no seguinte sentido: "[...] de forma que os requisitos acima elencados sejam exigidos de forma cumulativa somente quanto aos processos distribuídos a partir da data da publicação do acórdão embargado, ou seja, 4/5/2018." Porém, com Repercussão Geral no Supremo Tribunal Federal, Tema 6: "Dever do Estado de fornecer medicamento de alto custo a portador de doença grave que não possui condições financeiras para comprá-lo". (BRASIL, 2020, s.p.).
} 
O Supremo Tribunal Federal reconheceu, ao fixar o Tema 793 (BRASIL, 2019, s.p.), que a Saúde é um dos principais Direitos Fundamentais Prestacionais, o qual impõe a todos os Entes Federativos, como dever Fraterno e Solidário, corresponde à adoção de Políticas Públicas eficazes para o alcance da Justiça Social e Dignidade de todos, especialmente do Idoso. Nesse contexto, colhe-se do Tema 793 (BRASIL, 2019, s.p.):

Os entes da federação, em decorrência da competência comum, são solidariamente responsáveis nas demandas prestacionais na área da saúde, e diante dos critérios constitucionais de descentralização e hierarquização, compete à autoridade judicial direcionar o cumprimento conforme as regras de repartição de competências e determinar o ressarcimento a quem suportou o ônus financeiro.

Além do Tema 793, é indispensável destacar o julgamento do Tema 500, pelo Supremo Tribunal Federal, em sede de Recurso com Repercussão Geral, que versa sobre o "Dever do Estado de fornecer medicamento não registrado pela ANVISA", que foi julgado em 22 de maio de 2019, restando fixada a seguinte Tese (BRASIL, 2020, s.p.):

1. O Estado não pode ser obrigado a fornecer medicamentos experimentais. 2. A ausência de registro na ANVISA impede, como regra geral, o fornecimento de medicamento por decisão judicial. 3. É possível, excepcionalmente, a concessão judicial de medicamento sem registro sanitário, em caso de mora irrazoável da ANVISA em apreciar o pedido (prazo superior ao previsto na Lei $\mathrm{n}^{\mathrm{o}} 13.411 / 2016$ ), quando preenchidos três requisitos: (i) a existência de pedido de registro do medicamento no Brasil (salvo no caso de medicamentos órfãos para doenças raras e ultrarraras);(ii) a existência de registro do medicamento em renomadas agências de regulação no exterior; e (iii) a inexistência de substituto terapêutico com registro no Brasil. 4. As ações que demandem fornecimento de medicamentos sem registro na ANVISA deverão necessariamente ser propostas em face da União.

Portanto, verificando-se que o Poder Judiciário objetiva, também, uma Sociedade solidária e fraterna, e há mecanismos para tanto, com destaque aos Recursos Repetitivos e aos Recursos com Repercussão Geral, conforme acima exemplificados em matéria de Direito à Saúde. Nessa linha, conclui-se que é indispensável o Controle Judicial de Políticas Públicas da Saúde do Idoso, inclusive, na perspectiva da Sustentabilidade e em tempos de Pandemia, com o intuito de se aplicar o mesmo entendimento para todos àqueles que se encontram no território nacional, especialmente, para os Idosos. 


\section{CONSIDERAÇÕES FINAIS}

A mudança no perfil da população brasileira é perceptível, eis que cresce a cada dia o número de pessoas Idosas e as projeções são nítidas para o aumento da população de Idosos no Brasil. Esses dados e percentuais são indispensáveis para a formulação de Políticas Públicas, tão mais para àquelas que objetivam proteger, promover e defender o Direito à Saúde do Idoso.

O Poder Executivo, o Poder Legislativo e o Poder Judiciário possuem o papel constitucional de garantir a concretização dos Direitos Fundamentais, em especial da Saúde do Idoso, e, em caso de violação ou de omissão por parte do Poder Legislativo e/ou do Executivo, cumpre ao Poder Judiciário esta missão.

O Poder Judiciário objetiva, também, uma Sociedade solidária e fraterna, e há mecanismos para tanto, com destaque aos Recursos Repetitivos e aos Recursos com Repercussão Geral em matéria de Direito à Saúde. Por isso pode-se concluir que é indispensável o Controle Judicial de Políticas Públicas da Saúde do Idoso, inclusive, na perspectiva da Sustentabilidade e, tão mais, em tempos de Pandemia, com o intuito de se aplicar o mesmo entendimento para todo o Idoso que se encontra no território nacional.

A perspectiva da Sustentabilidade incrementa critérios racionais nos fundamentos das decisões envolvendo o Controle de Políticas Públicas à medida que considera não só a relevância intrínseca do Direito à Saúde do Idoso, mas também a sua necessária fruição coletiva, e bem como um horizonte temporal mais adequado, em plena sintonia, também, com os Objetivos do Desenvolvimento Sustentável (ODS).

\section{REFERÊNCIAS}

ARENHART, Sergio Cruz. Processos estruturais no direito brasileiro: reflexões a partir do caso da ACP do carvão. Disponível em: http://revistadeprocessocomparado.com.br/wpcontent/uploads/2016/01/ARENHART-Sergio-Artigo-Decisoes-estruturais.pdf. Acesso em: 16 set. 2020.

BODNAR, Zenildo. Tutela jurisdicional da probidade da Administração Pública Ambiental. In: Revista de Doutrina da $4^{\text {a }}$ Região, Porto Alegre, n. 50, out. 2012. Disponível em: www.revistadoutrina.trf4.jus.br/artigos/edicao050/Zenildo_Bodnar.html. Acesso em: 16 set. 2020. 
BODNAR, Zenildo. A (des)judicialização das políticas públicas de saúde na Vara Federal Cível de Criciúma - SC. Revista Tempus Actas de Saúde Coletiva. v. 7, n. 1, p. 299-315, 2013. Disponível em: www.tempusactas.unb.br/index.php/tempus/article/view/1298. Acesso em: 15 set. 2020.

BRASIL. Conselho Nacional de Justiça. Agenda 2030. Disponível em: www.cnj.jus.br/programas-e-acoes-2-2/agenda-2030/. Acesso em: 16 set. 2020.

BRASIL. Conselho Nacional de Justiça. Encontro Ibero-Americano da Agenda 2030 no Poder Judiciário. Agosto de 2019. Curitiba-PR. Disponível em: www.cnj.jus.br/programas-e-acoes/agenda-2030/. Acesso em: 16 set. 2020.

BRASIL. Constituição da República Federativa do Brasil de 1988. Disponível em: www.planalto.gov.br/ccivil_03/constituicao/constituicaocompilado.htm. Acesso em: 14 set. 2020.

BRASIL. Fundação Oswaldo Cruz. Covid-19: que vírus é esse? Disponível em: https://portal.fiocruz.br/noticia/covid-19-que-virus-e-esse. Acesso em: 15 set. 2020.

BRASIL. Instituto Brasileiro de Geografia e Estatística. IBGE/Diretoria de Pesquisas. Coordenação de População e Indicadores Sociais. Gerência de Estudos e Análises da Dinâmica Demográfica. Projeção da população do Brasil e Unidades da Federação por sexo e idade para o período 2010-2060. Disponível em: www.ibge.gov.br/estatisticas/sociais/populacao/9109-projecao-dapopulacao.html?edicao=21830\&t=resultados. Acesso em: 6 abr. 2020.

BRASIL. Instituto Brasileiro de Geografia e Estatística. Projeções e estimativas da população do Brasil e das Unidades da Federação. Disponível em: www.ibge.gov.br/apps/populacao/projecao/. Acesso em: 14 set. 2020.

BRASIL. Lei n. 8.842, de 4 de janeiro de 1994. Dispõe sobre a política nacional do idoso, cria o Conselho Nacional do Idoso e dá outras providências. Disponível em: www.planalto.gov.br/ccivil_03/Leis/L8842.htm. Acesso em: 15 set. 2020.

BRASIL. Lei n. 10.741, de $1^{0}$ de outubro de 2003. Dispõe sobre Estatuto do Idoso e dá outras providências. Disponível em: www.planalto.gov.br/ccivil_03/leis/2003/110.741.htm. Acesso em: 11 set. 2020.

BRASIL. Lei n. 13.105, de 16 de março de 2015. Código de Processo Civil. Disponível em: www.planalto.gov.br/ccivil_03/_ato2015-2018/2015/lei/113105.htm. Acesso em: 15 set. 2020.

BRASIL. Ministério da Saúde. Saúde da pessoa idosa: prevenção e promoção à saúde integral. Disponível em: https://saude.gov.br/saude-de-a-z/saude-da-pessoa-idosa. Acesso em: 11 set. 2020. 
BRASIL. Ministério da Saúde. Coronavírus Brasil. COVID-19 SRAG Síndrome Respiratória Aguda Grave. Atualizado em 09 set. 2020. Disponível em: https://covid.saude.gov.br/. Acesso em: 14 set. 2020.

BRASIL. Portaria n. 2.528, de 19 de outubro de 2006. Aprova a Política Nacional de Saúde da Pessoa Idosa. Disponível em: //bvsms.saude.gov.br/bvs/saudelegis/gm/2006/prt2528_19_10_2006.html. Acesso em: 16 set. 2020.

BRASIL. Superior Tribunal de Justiça. Tema 106. Disponível em: Www.stj.jus.br/repetitivos/temas_repetitivos/pesquisa.jsp?novaConsulta=true\&tipo_pesqui sa=T\&cod_tema_inicial=106\&cod_tema_final=106. Acesso em: 16 set. 2020.

BRASIL. Supremo Tribunal Federal. Tema 500. RE 657.718. Disponível em: www.stf.jus.br/portal/jurisprudenciaRepercussao/verAndamentoProcesso.asp?incidente $=41$ 43144\&numeroProcesso=657718\&classeProcesso=RE\&numeroTema=500. Acesso em: 16 set. 2020 .

BRASIL. Supremo Tribunal Federal. Tema 793. RE 855.178. Min. Edson Fachin. Data do julgamento: 23 maio 2019.2 Disponível em: www.stf.jus.br/portal/jurisprudenciaRepercussao/verAndamentoProcesso. asp?incidente $=46$ 78356\&numeroProcesso $=855178 \&$ classeProcesso $=$ RE\&numeroTema=793. Acesso em: 16 set. 2020.

BUSSE, Alexandre Leopold e JACOB FILHO, Wilson. Envelhecimento: uma visão multidisciplinar. In: Envelhecimento: uma visão multidisciplinar. Editor Wilson Jacob Filho. Rio de Janeiro: Editora Atheneu, 2015.

CANOTILHO, José Joaquim Gomes. Direito constitucional e teoria da constituição. 7. ed. 21 reimp. Coimbra: Almedina, 2019.

COMITÊ NACIONAL DE ORGANIZAÇÃO RIO+20. Conferência das Nações Unidas sobre o Desenvolvimento Sustentável. Disponível em: www.rio20.gov.br/sobre_a_rio_mais_20/desenvolvimento-sustentavel.html. Acesso em 16 set. 2020.

CRUZ, Paulo Márcio; BODNAR, Zenildo. Globalização, transnacionalidade e sustentabilidade [recurso eletrônico]; participação especial Gabriel Real Ferrer; org. e rev. Lucas de Melo Prado. - Dados eletrônicos. - Itajaí: UNIVALI, 2012. Disponível em: www.univali.br/vida-no-campus/editora-univali/e-books/Documents/ecjs/Ebook\%202012\%20GLOBALIZA\%C3\%87\%C3\%830,\%20TRANSNACIONALIDADE\% 20E\%20SUSTENTABILIDADE.pdf. Acesso em: 16 set. 2020.

DIÁRIO DO NORDESTE. Idoso com suspeita de Covid-19 morre à espera de leito de UTI na UPA do Bom Jardim, matéria publicada em 03 de maio de 2020. Disponível em: https://diariodonordeste.verdesmares.com.br/metro/idoso-com-suspeita-de-covid-19- 
morre-a-espera-de-leito-de-uti-na-upa-do-bom-jardim-1.2241482. Acesso em: 15 set. 2020.

DIAS, Jean Carlos. O controle judicial de políticas públicas. 2. ed. rev. atual. e ampl. Salvador: JusPODIVM, 2016, 224 p.

FEIL, Alexandre André e SCHREIBER, Dusan. Sustentabilidade e desenvolvimento sustentável: desvendando as sobreposições e alcances de seus significados. Disponível em: www.scielo.br/scielo.php?pid=S1679-39512017000300667\&script=sci_abstract\&tlng=pt. Acesso em 16 set. 2020.

FREITAS, Juarez. Políticas públicas e controle judicial de prioridades constitucionais. In: Revista da Escola da Magistratura do TRF da 4. Região, vol. I, n. I. Porto Alegre: Tribunal Regional Federal da $4^{\mathrm{a}}$ Região, 2014. p. 141-157.

FREITAS, Juarez. Sustentabilidade das políticas públicas: nova modalidade de escrutínio. In: BODNAR, Zenildo; CELANT, João Henrique Pickcius; MARCOS, Rudson. O Judiciário como instância de governança e sustentabilidade: descobertas, dúvidas e discordâncias. Florianópolis. Editora EMais, 2018.

HERINGER, Flávio Roberto de Almeida. Quantas políticas públicas há no Brasil? O problema da imprecisão conceitual para a avaliação de políticas públicas. Brasília: Senado Federal, 2018.2 Disponível em: www2.senado.leg.br/bdsf/bitstream/handle/id/555174/ILB2018_HERINGER.pdf?sequenc e=1. Acesso em: 16 set. 2020 .

LOPES, Alexandra. Evelhecimento, dependência e fragilidades: tensões e desafios no Portugal contemporâneo. In: Evenelhecimento na Sociedade Portuguesa: pensões, família e cuidados. Pedro Moura Ferreira et al Org. Lisboa: ICS, 2017.

NAÇÕES UNIDAS BRASIL. A ONU e a pessoa idosa. Disponível em: //nacoesunidas.org/acao/pessoas-idosas/. Acesso em: 26 mar. 2020.

NAÇÕES UNIDAS BRASIL. A ONU e o Meio Ambiente. Disponível em: //nacoesunidas.org/acao/meio-ambiente/. Acesso em: 16 set. 2020.

NAÇÕES UNIDAS BRASIL. Conheça os novos 17 Objetivos de Desenvolvimento Sustentável da ONU. Disponível em: //nacoesunidas.org/conheca-os-novos-17-objetivosde-desenvolvimento-sustentavel-da-onu/. Acesso em: 16 set. 2020.

NAÇÕES UNIDAS BRASIL. Especialista da ONU pede melhor proteção para idosos na pandemia do novo coronavírus. Publicada em 09 de abril de 2020. Disponível em: //nacoesunidas.org/especialista-da-onu-pede-melhor-protecao-para-idosos-na-pandemiado-novo-coronavirus/. Acesso em: 16 set. 2020.

PAPALIA, Diane E.; FELDMAN, Ruth Duskin. Desenvolvimento humano. Tradução de Carla Filomena Marques Pinto Vercesi [et al]. 12 ed. Porto Alegre: AMGH, 2013. 
PASOLD, Cesar Luiz. Metodologia da Pesquisa Jurídica: Teoria e Prática. 14. ed. rev.atual.e amp. Florianópolis: Emais, 2018.

UNITED STATES. Department of Health and Human Services. Centers for Disease Control and Prevention. Older Adults. Page last reviewed [última revisão da página]: Sept. 11, 2020. Disponível em: www.cdc.gov/coronavirus/2019-ncov/need-extra-precautions/olderadults.html. Acesso em: 14 set. 2020.

UNITED NATIONS. 'We need to stand up now' for older persons: urges UN rights expert on World Day. 30/09/2019. Disponível em: //news.un.org/en/story/2019/09/1048252. Acesso em: 16 set. 2020.

UVO BODNAR, Roberta Terezinha. A tutela jurisdicional da saúde do idoso no Brasil e a matriz disciplinar interpretativa dos Tribunais na perspectiva da fraternidade. 2015 . Dissertação (Curso de Pós-Graduação em Direito). Universidade Federal de Santa Catarina: Florianópolis. Disponível em: //repositorio.ufsc.br/xmlui/handle/123456789/157417. Acesso em: 15 set. 2020.

UVO BODNAR, Roberta Terezinha. Prefácio. In: SOUZA, Aulus Eduardo Teixeira de. Políticas públicas e guardas municipais: instrumentos efetivos de preservação do meio ambiente urbano. Rio de Janeiro: Lumen Juris, 2019.

WORLD HEALTH ORGANIZATION. Ageing and health. Disponível em: www.who.int/news-room/fact-sheets/detail/ageing-and-health. Acesso em: 6 abr. 2020.

WORLD HEALTH ORGANIZATION. Decade of Healthy Ageing. Disponível em: www.who.int/initiatives/decade-of-healthy-ageing. Acesso em: 14 set. 2020.

WORLD HEALTH ORGANIZATION.WHO delivers advice and support for older people during COVID-19. Disponível em: https://www.who.int/news-room/featurestories/detail/who-delivers-advice-and-support-for-older-people-during-covid-19. Acesso em: 20 abr. 2020.

WORLD HEALTH ORGANIZATION. WHO remains firmly committed to the principles set out in the preamble to the Constitution. Disponível em: www.who.int/about/who-we-are/constitution. Acesso em: 14 set. 2020.

Data da submissão: 08/03/2021

Data da primeira avaliação: $25 / 06 / 2021$

Data da segunda avaliação: 30/08/2021

Data da aprovação: 06/09/2021 